\title{
Phase 1 Space Fission Propulsion System Design Considerations
}

\author{
Mike Houts, Melissa Van Dyke, Tom Godfroy, Kevin Pedersen, James Martin, \\ Ricky Dickens, Pat Salvail, Ivana Hrbud, Robert Carter
}

NASA MSFC, TD40, Marshall Space Flight Center, Alabama, 35812

(256)544-7143 / Fax: (256)544-5926 michael.houts@msfc.nasa.gov

\begin{abstract}
Fission technology can enable rapid, affordable access to any point in the solar system. If fission propulsion systems are to be developed to their full potential; however, near-term customers must be identified and initial fission systems successfully developed, launched, and operated. Studies conducted in fiscal year 2001 (IISTP, 2001) show that fission electric propulsion (FEP) systems operating at $80 \mathrm{kWe}$ or above could enhance or enable numerous robotic outer solar system missions of interest. At these power levels it is possible to develop safe, affordable systems that meet mission performance requirements. In selecting the system design to pursue, seven evaluation criteria were identified: safety, reliability, testability, specific mass, cost, schedule, and programmatic risk. A top-level comparison of three potential concepts was performed: an SP-100 based pumped liquid lithium system, a direct gas cooled system, and a heatpipe cooled system. For power levels up to at least $500 \mathrm{kWt}$ (enabling electric power levels of $125-175 \mathrm{kWe}$, given $25-35 \%$ power conversion efficiency) the heatpipe system has advantages related to several criteria and is competitive with respect to all. Hardware-based research and development has further increased confidence in the heatpipe approach. Successful development and utilization of a "Phase 1" fission electric propulsion system will enable advanced Phase 2 and Phase 3 systems capable of providing rapid, affordable access to any point in the solar system.
\end{abstract}

\section{INTRODUCTION}

The fission process was first reported in 1939, and in 1942 the world's first man-made self-sustaining fission reaction was achieved. Creating a self-sustaining fission chain reaction is conceptually quite simple. All that is required is for the right materials to be placed in the right geometry - no extreme temperatures or pressures required - and the system will operate. Since 1942 fission systems have been used extensively by governments, industry and universities. Fission systems operate independently of solar proximity or orientation, and are thus well suited for deep space or planetary surface missions. In addition, the fuel for fission systems (highly enriched uranium) is essentially non-radioactive, containing $0.064 \mathrm{curies} / \mathrm{kg}$. This compares quite favorably to current nuclear systems (Pu-238 in radioisotope systems contains 17,000 curies $/ \mathrm{kg}$ ) and certain highly futuristic propulsion systems (tritium in D-T fusion systems would contain $10,000,000$ curies $/ \mathrm{kg}$ ). An additional comparison is that at launch a typical space fission propulsion system would contain an order of magnitude less onboard radioactivity than did Mars Pathfinder's Sojoumer Rover, which used radioisotopes for thermal control. The primary safety issue with fission systems is avoiding inadvertent system start - addressing this issue through proper system design is quite straightforward. The energy density of fission is seven orders of magnitude greater than that of the best chemical fuels, and if properly utilized is more than adequate for enabling rapid, affordable access to any point in the solar system.

Despite the relative simplicity and tremendous potential of space fission systems, the development and utilization of these systems has proven elusive. The first use of fission technology in space occurred 3 April 1965 with the US launch of the SNAP-10A reactor. There have been no additional US uses of space fission systems. While space fission systems were used extensively by the former Soviet Union, their application was limited to earth-orbital missions. Early space fission systems must be safely and affordably utilized if we are to reap the benefits of advanced space fission systems. 
Table 1 gives a partial list of major US space fission programs that have failed to result in flight of a system (Angelo, 1985). There are a variety of reasons why these programs failed to result in a flight. The fact that so many programs have failed indicates that a significantly different approach must be taken if future programs are to succeed. In many cases, space reactor programs were cancelled because the proposed mission was cancelled. However, in many of those cases mission cancellation was partially due to the fact that the reactor required by the mission was taking too long and costing too much to develop.

Near-term space fission systems must capitalize on experience gained from previous fission programs. The development of new nuclear technology has historically been costly and time consuming. Nuclear technology developed by previous programs should thus be utilized, and no new nuclear technology should be required. This means that all in-core components should operate within demonstrated fuel burnup capability and demonstrated neutron damage limits for the given reactor environment (temperature, chemistry, power density, etc.). The construction of new nuclear facilities or the extensive modification of existing facilities has historically been costly and time consuming. Near-term fission systems should thus use only existing nuclear facilities in their development. No new or significantly modified facilities should be required. Flight qualification of any space system requires an extensive test program. Near-term fission system flight units must thus be highly testable. Because of the expense and difficulty associated with performing realistic full-power ground nuclear tests, previous programs have considered the option of foregoing full-power ground nuclear testing in favor of a flight test. For example, in Josloff, 1993 (referring to the SP-100 program) it is stated that "There has been recent interest among government agencies in establishing an early flight mission that would provide the catalyst needed to enable confident planning for subsequent operational missions. This first flight would validate the total system performance, obviate the need for costly ground nuclear testing, demonstrate safety features and facilitate safety approval through the INSRP process for the subsequent operational missions." Full power nuclear ground test facility requirements may also dictate that the unit tested on the ground be significantly different than the actual flight unit. Any differences between what is tested and what is flown will limit the benefit from full-power ground nuclear tests. Highly testable systems that utilize established nuclear technology incur the least technical risk if full power ground nuclear testing is not performed. The ability to quickly and affordably establish the safety and reliability of any proposed space fission system will be critical to its programmatic success.

Additional innovative approaches will have to be used to ensure that the next space fission system development program results in system utilization. Safety must be the primary focus of the program, but cost and schedule must also be significant drivers. System performance must be adequate, but the desire to make performance more than adequate should not be allowed to drive system cost and schedule. Near-term space fission systems must be safe, simple, and as inexpensive to develop and utilize as possible.

TABLE 1. Partial list of major US Space Fission Programs that Have Failed to Result in Flight of a System.

- Solid-Core Nuclear Rocket Program

- Medium-Power Reactor Experiment (MPRE)

- Thermionic Technology Program (1963-1973)

- Space Nuclear Thermal Rocket Program

- SP-100
- SNAP-50 / SPUR

- High-Temperature GasCooled Electric Power Reactor (710 Reactor)

- SPAR / SP-100

- Flight Topaz

- DOE $40 \mathrm{kWe}$ Thermionic Reactor Program
- Advanced Liquid Metal Cooled Reactor

- Advanced Space Nuclear Power Program (SPR)

- Multi-Megawatt Program

- Thermionic Fuel Element Verification Program

- Air Force Bimodal Study

Evaluation of potential first generation (Phase 1) space fission systems began at Los Alamos National Laboratory in 1995 (Houts, 1996). The original evaluations were based on up to 16 criteria. For the sake of brevity and for more direct applicability to ongoing efforts, the original criteria can be condensed into seven primary criteria: safety, reliability, testability, specific mass, cost, schedule, and programmatic risk. 


\section{CONCEPT COMPARISON BASED ON SEVEN EVALUATION CRITERIA}

The evaluation assumes a required system power level of $500 \mathrm{kWt}$ or less - a significant increase in required thermal power could disallow many potential design simplifications, require additional technology development, and reduce system testbility. The evaluation also assumes that thermal power will be delivered to the power conversion subsystem at temperatures up to $1300 \mathrm{~K}$. This temperature is near the upper limit of what can be utilized by applicable state-of-the-art power conversion subsystems, thus choosing this temperature helps minimize potential reactor-related impacts on power conversion subsystem operating temperature and performance. Brayton power conversion is chosen as the baseline, although alternatives could be considered for certain systems. Top-level evaluations were previously performed on multiple systems. Observations related to three potential reactor concepts currently under discussion are reported in this paper: an SP-100 based pumped liquid lithium system, a direct gas cooled system, and a heatpipe cooled system.

\section{Safety}

Arguments have been made that the low probability of launch accidents that could cause inadvertent criticality of a space fission system, coupled with the relatively low consequence of those accidents, reduces the need to design systems to ensure subcriticality during all credible launch accidents. At present; however, precluding inadvertent criticality remains the primary safety concern with developing and utilizing space fission systems. Inadvertent criticality must be precluded during all phases of testing, development, fabrication, launch, and (if applicable) earth re-entry. In addition to nuclear safety, industrial hazards (such as hazardous or flammable materials) must be taken into account.

The SP-100 requires in-core shutdown rods to ensure subcriticality during credible launch accidents. These rods must simultaneously be designed to remain in-core during any credible launch accident and to be reliably removed when desired. SP-100 fuel is sealed within the core during fabrication and cannot be easily removed during transportation and handling. Lithium fill occurs after the core is fueled. The SP-100 has a large metallic lithium inventory contained within a single $(\mathrm{Nb}-1 \mathrm{Zr})$ barrier. An emergency core cooling system is required to prevent fuel damage if lithium circulation is lost. Shutdown rods or other launch safety mechanisms would need to be re-inserted prior to an inadvertent re-entry to guarantee subcriticality.

Direct gas-cooled concepts will most likely require in-core shutdown rods, although the use of neutron spectral shift may be adequate for ensuring subcriticality during launch failures that do not assume "worst-case" (and potentially non-credible) reactor configurations following the launch failure. An emergency core cooling system is required to prevent fuel damage if gas circulation is lost. Shutdown rods or other launch safety mechanisms would need to be re-inserted prior to an inadvertent re-entry to guarantee subcriticality.

The heatpipe system has pin-to-pin contact and filled interstitials within the core, greatly reducing the reactivity insertion from a core compaction accident. The combination of fast spectrum operation, small in-core void fraction, and high radial reflector worth allows for "passive" shutdown, e.g. full safety with fuel launched in the core and no in-core shutdown rods during all credible compaction and/or water/sand immersion scenarios. This in turn allows for "passive" startup - startup is achieved solely by actuating the control system, with no additional mechanisms required to remove in-core shutdown rods or disable other launch safety features. Should an inadvertent re-entry occur after attempted system -start, the heatpipe system remains subcritical without re-insertion of shutdown rods or other launch safety mechanisms. The heatpipe design also allows fuel to be removed from the core at any desired time prior to operation. Heatpipes passively remove decay heat from the core, eliminating the need for a separate emergency core cooling system.

\section{Reliability}

SP-100's complex integration issues reduce reliability. In addition to in-core shutdown rods that most be removed prior to operation, SP-100 requires a lithium thaw system that must function to allow startup and a lithium / helium gas separator system for long-term operation. The $\mathrm{Nb}-1 \mathrm{Zr}$ lithium containment vessel is a single-point failure, and 
there is no significant data on pressure vessel lifetime in the lithium loop environment. The SP-100 requires high performance thermoelectic electromagnetic pumps to circulate the liquid lithium coolant. Because of the single core cooling loop, a failure in the liquid-metal-to-gas heat exchanger may also propagate into full system failure (loss of lithium coolant via leakage into Brayton loop, or mixing of Brayton helium/xenon with lithium).

In gas cooled systems, direct gas cooling of the core precludes the use of independent Brayton conversion units. There is a risk of debris from a failed Brayton unit entering the core, with the potential for flow channel blockage and fuel damage. Turbomachinery failure could also result in the loss of helium/xenon coolant from the system. There is potential for material transport between the Brayton and core during normal operation. Fuel pin failure results in the contamination of the Brayton working gas and the potential for metallic uranium if UN fuel is used. The gas barrier at any/all locations is a single-point failure. Direct gas-cooled concepts will require an emergency core cooling system to prevent fuel damage if gas circulation is lost (necessary for recovery / restart).

Heatpipe systems can be designed with no single point failures. One option is for the heatpipes to be used to power multiple independent heat exchangers for three independent Brayton loops. With this approach failure of a Brayton unit does not result in a risk of debris entering the core, and fuel pin failure does not effect Brayton operation. Catastrophic failure of a heat exchanger would results in a loss of $1 / 3$ system power production. Power from the affected heatpipes would be delivered to the two Brayton units that remained operational. Heatpipe systems give the option for adding a superalloy gas barrier around core/heat exchanger, which would provide double containment of the $\mathrm{He} / \mathrm{Xe}$ working fluid, and a non-refractory metal barrier to gas leakage. Heatpipes also remove decay heat from the core - loss of Brayton gas circulation does not result in fuel damage. The core of the heatpipe system is highly accessible to instrumentation designed to improve operational reliability.

\section{Testability}

An SP-100 based system would not allow realistic (resistance-heated) full-thrust testing of the actual flight unit, or realistic testing of development units. This is because the fuel pins are immersed in liquid lithium during operation, and it would be impossible to operate the system using resistance heaters to simulate heat from fission without extensive and risky operations to drain the liquid lithium, remove the lithium containment vessel head, remove heaters from the pins, insert fuel in the pins, seal the pins, refill the system with lithium, and re-weld the $\mathrm{Nb}-1 \mathrm{Zr}$ pressure vessel, all without contaminating the system with unacceptable levels of lithium compounds. In addition, the lithium flow distribution system would require significant re-design to allow room for heaters and leads that would be required for each fuel pin. A testing alternative would be to provide penetrations in the $\mathrm{Nb}-1 \mathrm{Zr}$ vessel head for each fuel pin so heaters and fuel could be loaded/unloaded without breaching the lithium boundary. However, this could be extremely difficult to fabricate from $\mathrm{Nb}-1 \mathrm{Zr}$, and each penetration would be a single-point failure. The SP-100 is a highly integrated (non-modular) system, reducing the ability to perform significant development via module testing. The optimal testing approach for the SP-100 remains to be developed. It may also be difficult to perform realistic, steady-state testing of the lithium/helium separator in a microgravity environment.

The direct gas-cooled system has testability issues similar to those of the SP-100, although the fact that the fuel is cooled by inert gas instead of lithium would make some of the issues much more tractable. Testing approaches that require the core to be entirely replaced by a heater bank with similar thermal hydraulic characteristics are nonprototypic, as they provide no assurance that the actual as-fabricated core will have the required thermal hydraulic performance, expansion characteristics, and thermal stress resistance. If a gas distribution system can be designed that allows room for heaters and leads to be inserted through the plenum, then it may be possible to access the fuel pins from outside the pressure boundary. Although hundreds of penetrations would be required in the pressure boundary, fabrication would be made easier if the pressure boundary did not need to be fabricated from refractory metal (although a refractory metal to non-refractory metal seal might still be needed). It might also be possible to have an additional pressure boundary (non-refractory) that would be filled with $\mathrm{He} / \mathrm{Xe}$ and welded shut after the core had been fueled. Direct gas-cooled systems are highly integrated, reducing the ability to perform significant development via module testing. The optimal testing approach for direct gas-cooled systems remains to be developed.

The heatpipe system allows realistic full-thrust testing (resistance heated) of the actual flight unit prior to launch, with minimal subsequent operations required to remove heaters, insert fuel, and ready the system for launch. Full- 
thrust integrated system testing of the flight unit is designed to demonstrate predicted performance of the asfabricated flight unit, and to identify any fabrication or assembly flaws. If needed, the heatpipe system is heated prior to launch to ensure ductility while subject to launch loads. The heatpipe system is highly modular, and most technology issues can be resolved at a module level. This includes in-reactor irradiations of prototypic heatpipe modules at prototypic conditions. The heatpipe to gas heat exchanger must be designed to maintain modularity and separability.

\section{Specific Mass}

Specific mass of the systems is strongly affected by ex-reactor components, e.g. the Brayton cycle, radiator, thrusters, boom, propellant tanks, etc. SP-100 potentially suffers a mass penalty because it has more system components and integration hardware. The direct gas-cooled concept potentially saves mass by not requiring a heat exchanger between the core coolant and the Brayton cycle. The heatpipe concept potentially saves mass by not requiring in-core shutdown rods for safety, and having the highest core fuel fraction. The heatpipe concept also provides the option for in-space fueling, potentially enabling a several hundred kilogram mass savings during the NEP portion of the mission (re-entry cone, fueling mechanism jettisoned after use), albeit at the expense of reduced startup reliability compared to the baseline heatpipe concept.

\section{Cost}

SP-100 costs were shown to be exceedingly high by the previous SP-100 program. The need for a complex refractory metal lithium containment vessel, difficulty in performing realistic non-nuclear testing, complexity of system integration, and other factors all qualitatively suggest that SP-100 costs would be difficult to reduce. The modularity of the heatpipe system, coupled with its propensity for hardware-based development and realistic nonnuclear testing will help reduce cost compared to alternatives. Separation of the core from the power conversion subsystem and the high level of fault tolerance will also reduce heatpipe system development and testing costs compared to alternatives.

\section{Schedule}

The required SP-100 schedule was shown to be exceedingly long by the previous program. After 11 years and \$500M (FY92) very little progress had been made towards actually fielding a flight unit. SP-100's need for a complex refractory metal lithium containment vessel, difficulty in performing realistic non-nuclear testing, complexity of system integration, and other factors all qualitatively suggest that SP-100 development time would be difficult to reduce. The modularity of the heatpipe system, coupled with its propensity for hardware-based development and realistic non-nuclear testing will help reduce schedule compared to alternatives. Separation of the core from the power conversion subsystem and the high level of fault tolerance will also reduce heatpipe system development and testing schedule compared to alternatives.

\section{Programmatic Risk}

Liquid metal cooled terrestrial reactors (e.g. FFTF, EBR-II) have not used lithium coolant, have not used refractory metal fuel clad/vessels, have not used EM pumps, have not operated in zero gravity, and have not operated at the temperatures required by Phase 1 fission electric propulsion systems. The SP-100 is thus significantly different from terrestrial liquid metal cooled reactors. Terrestrial gas-cooled reactors (e.g. Fort St. Vrain) typically have not used pin fuel or refractory metal fuel clad, have not operated at the temperatures required by the Phase 1 system, and have utilized a thermal neutron spectrum. Direct gas-cooled space reactors would thus be significantly different than terrestrial gas-cooled systems. Although heatpipes have been used in-core, they have never been used as the primary means of heat transport out of a reactor. Because no system similar to any of the three options being considered has ever been built and operated terrestrially, a certain level of programmatic risk exists for all options. 
SP-100 programmatic risk is perhaps best summarized by historical data. The eleven-year, $\$ 500 \mathrm{M}$ (FY92) program made very little progress towards developing an actual flight unit. While a tremendous amount of paper was generated, the program did not even progress to the point of performing a realistic primary heat transport test or zero-power criticals on an engineering unit. Fuel for the SP-100 was developed, qualified, and fabricated; however, fuel fabrication would need to be re-qualified if SP-100 type fuel is to be used on future systems. The SP-100 fuel that was fabricated is contaminated with traces of plutonium, potentially making it programmatically unacceptable for use. Perhaps the most serious concern with the SP-100 is its complex system integration. This issue would not be truly resolved until late in the program. Issues identified elsewhere in this evaluation will not be repeated, but also combine to give SP-100 a very high programmatic risk.

Programmatic risk associated with direct gas-cooled concepts results from negative attributes identified elsewhere in this comparison. The direct gas-cooled system is only suitable for use with a Brayton cycle - alternative power conversion systems cannot be considered as backups and would be difficult to use even for providing emergency power. Direct gas-cooled concepts are highly integrated (non-modular) and many potential issues will only be resolved via coupled reactor/Brayton testing. Unfortunately, as previously noted it is difficult to design direct gascooled systems to allow realistic non-nuclear testing. Minimum Brayton cycle operating pressure will be set by the core design to allow an acceptable core void fraction; however, this may be a higher pressure than might otherwise be desirable to operate the Brayton cycle. Direct gas-cooled concepts may be competitive at high power levels ( $>2$ $\mathrm{MWt}$ ), although required operating pressure and core void fraction at these power levels may be a concern. heatpipe system is highly modular and has fewer reactor-side integration issues than alternatives. Early, significant milestones can be achieved via module testing. Heatpipe system is highly flexible and allows power from the system to be used in a variety of ways - including flexibility in choice of power conversion subsystem (potential for multiple customers). Advantages of the heatpipe approach are reduced at higher power levels. Power levels in excess of $1000 \mathrm{kWt}$ may require heatpipe systems to utilize in-core shutdown rods or in-space fueling for safety and/or "supermodules" containing more than one heatpipe to provide full power after worst-case or multiple heatpipe failure. Heatpipe to fuel ratio may also need to be increased. A significant increase in required power level late in the program could require core re-design.

\section{THE 400 KILOWATT THERMAL SAFE AFFORDABLE FISSION ENGINE (SAFE-400)}

Hardware-based research and development related to Phase 1 space fission system development has been ongoing since 1996 (Houts, 1997). Details of recent efforts at NASA MSFC are given in Van Dyke, 2002. Details of the reference Phase $1400 \mathrm{kWt}$ design (SAFE-400) are given in Poston, 2002.

\section{RECOMMENDATIONS FOR FUTURE RESEARCH}

Research should continue on near-term, affordable space fission systems. These systems are characterized primarily by the use of existing nuclear technology, the use of existing nuclear facilities, and a very high level of testability. The focus of this research should be on demonstrating that fission propulsion systems can be developed and utilized in a safe, timely, and affordable fashion.

\section{ACKNOWLEDGMENTS}

Unless otherwise referenced, the research reported in this paper was funded by and performed at NASA's Marshall Space Flight Center.

\section{REFERENCES}

Angelo, J.A. and Buden, D. (1985) Space Nuclear Power, ISBN 0-89464-000-03, Orbit Book Company, Inc., Malabar, Florida. 
Houts, M.G., Poston, D.I., Ranken, W.A. (1996) "Heatpipe Space Power and Propulsion Systems," in Space Nuclear Power and Propulsion, edited by Mohamed S. El-Genk and Mark D. Hoover, DOE Conf 960109, American Institute of Physics, New York, pp. 1155-1162.

Houts, M.G., Poston, D.I., Emrich, W.J. (1997) "Heatpipe Power System and Heatpipe Bimodal System Design and Development Options," in Space Nuclear Power and Propulsion, edited by Mohamed S. El-Genk and Mark D. Hoover, DOE Conf 970115 , American Institute of Physics, New York, pp. 1317-1322.

Integrated In-Space Transportation Planning (IISTP), 2001, "Summary of Process and Technology Prioritization," presentation, NASA Marshall Space Flight Center, May 31, 2001.

Josloff, A.T., Matteo, D.N., Bailey, H.S. (1993) "SP-100 Space Reactor Power System Readiness and Mission Flexibility," in Space Nuclear Power and Propulsion, edited by Mohamed S. El-Genk, DOE Conf 930103, American Institute of Physics, New York, pp. 229-236.

Poston, D. I. et al. (2002) "Design and Analysis of the SAFE-400 Reactor," to be published in Space Nuclear Power and Propulsion, edited by Mohamed S. El-Genk, American Institute of Physics, New York, 2002, within these proceedings.

Vandyke, M.K. et al. (2002) "Safe Affordable Fission Engine (SAFE) Testing and Development Progress," to be published in Space Nuclear Power and Propulsion, edited by Mohamed S. El-Genk, American Institute of Physics, New York, 2002, within these proceedings. 